\title{
Strategi Peningkatan Kinerja Balai Benih Ikan Dinas Kelautan dan Perikanan Kabupaten Sukabumi
}

\author{
Performance Improvement Strategy of Fish Nurtury Center \\ Fisheries and Marine Department of Sukabumi District
}

Sri Padmoko ${ }^{1}$, Marimin $^{2}$, dan MH Bintoro ${ }^{3}$

\author{
${ }^{1}$ Program Studi Pengembangan Industri Kecil Menengah, Sekolah Pascasarjana IPB \\ ${ }^{2}$ Departemen Teknologi Industri Pertanian Fakultas Teknologi Pertanian IPB \\ ${ }^{3}$ Departemen Agronomi dan Hortikultura Fakultas Pertanian IPB \\ email: sripadmoko@gmail.com
}

\begin{abstract}
ABSTRAK
Unit Pelaksana Teknis Daerah (UPTD) Balai Benih Ikan (BBI) Cimaja sebagai salah satu ujung tombak penghasil benih ikan bermutu dan induk ikan unggulan di wilayah Sukabumi serta sumber Pendapatan Asli Daerah (PAD). Keberadaan dan kinerja UPTD BBI Cimaja pada Dinas Perikanan dan Kelautan Kabupaten Sukabumi menjadi sangat penting terkait dengan peningkatan produksi ikan konsumsi air tawar. Tujuan penelitian ini adalah: (1) Menghitung kinerja UPTD BBI Cimaja berdasarkan perspektif Balanced Scorecard (BSC); (2) Mengetahui faktor-faktor yang memengaruhi kinerja UPTD BBI Cimaja berdasarkan perspektif Balanced Scorecard; dan (3) Menyusun strategi peningkatan kinerja UPTD BBI Cimaja berdasarkan perspektif BSC. Pengukuran kinerja menggunakan perpsektif BSC diolah dengan alat bantu perangkat lunak Analitycal Hierarchy Process (AHP) dan penentuan strategi peningkatan kinerja dalam rangka memenuhi tugas pokok dan fungsi BBI diolah dengan alat bantu strengths, weaknesses, opportunities, dan threats (SWOT) dan AHP. Hasil penghitungan kinerja UPTD BBI Cimaja berdasarkan perspektif balance scorecard diketahui belum maksimal dan perlu ditingkatkan melalui strategi pertumbuhan dan pembangunan intensif dan agresif. Hasil penelitian menunjukkan terdapat 23 faktor yang memengaruhi kinerja UPTD BBI Cimaja, yang terdiri atas perspektif keuangan dua faktor, perspektif pelanggan 10 faktor, perspektif proses internal enam faktor dan perspektif pembelajaran dan pertumbuhan lima faktor. Hasil AHP dan SWOT menunjukkan strategi peningkatan kinerja bersandar pada perspektif pelanggan dan secara konkrit adalah pemindahan lokasi yang memiliki jaminan ketersediaan sumber air dan dilanjutkan dengan pembangunan kolam pembenihan baru melalui dukungan Anggaran Pendapatan dan Belanja Daerah (APBD) agar bisa menjaga reputasi BBI, meningkatkan produksi dan ragam benih untuk meningkatkan jumlah konsumen terlayani.
\end{abstract}

Kata kunci: balance scorecard, benih ikan, strategi, kinerja, Sukabumi

\begin{abstract}
Regional Technical Implementation Unit (UPTD) of Fish Nurtury Center (BBI) Cimaja plays important role in providing high quality fish seeds and broodstock in Sukabumi as well as in supporting District Own Source Revenue (PAD). Presence and performance of UPTD BBI Cimaja are highly meaningful for enhancing production of edible freshwater fish. The aim of research is to (1) determine performance of UPTD BBI Cimaja based on Balanced Scorecard; (2) investigate factors affecting performance of UPTD BBI Cimaja based on Balanced Scorecard; and (3) develop strategy for improving performance of UPTD BBI Cimaja based on Balanced Scorecard. The performance was determined based on balanced scorecard using AHP software, while the strategy development for improving main task and function of BBI Cimaja was processed using SWOT and AHP. Based on balanced scorecard perspective, the maximum performance of UPTD BBI Cimaja has not been reached, thus the improvement through

\footnotetext{
*) Korespondensi:

Jl.Raya Cisolok KM 11 Pelabuhan Ratu, Cimaja, Cisolok, Sukabumi; e-mail: sripadmoko@gmail.com
} 
intensive and aggressive strategy of growth and development is required. The results showed 23 factors influencing performance of UPTD BBI Cimaja, consisting of 2 financial factors, 10 customer factors, 6 internal factors, and 5 learning and growth factors. Based on AHP and SWOT analysis, the concrete strategy for performance enhancement regarding to customer perspective was translocation that provides sufficient water sources, and new fish pond construction supported by Regional Government Budget (APBD) to maintain BBI reputation, as well as increase in seed diversity and production to improve number of customers.

Key words: balanced scorecard, fish seeds, performance, strategy, Sukabumi

\section{PENDAHULUAN}

Perikanan budidaya berpotensi sebagai salah satu prime mover perekonomian dan kesejahteraan masyarakat secara berkelanjutan yaitu: (1) Kontribusi perikanan budidaya terhadap Produk Domestik Bruto (PDB) nasional semakin meningkat dengan laju pertumbuhan yang lebih tinggi dibandingkan perikanan tangkap. Pada periode 2010-2012 laju pertumbuhan nasional PDB untuk perikanan budidaya rata-rata adalah $11,82 \%$, sedangkan laju pertumbuhan PDB perikanan tangkap rata-rata hanya sebesar 2,60\% (Pusdatin KKP, 2014); (2) Sumberdaya lahan perikanan budidaya di wilayah Kabupaten Sukabumi masih besar dan belum sepenuhnya dimanfaatkan. Luas lahan potensial untuk budidaya ikan Kabupaten Sukabumi tercatat sekitar 41,295 hektar dengan rincian: 200 hektar untuk budidaya laut; 1,400 hektar untuk budidaya air payau, dan 39,695 hektar untuk budidaya air tawar. Meskipun demikian hingga tahun 2015, pemanfaatan baru $6,00 \%$ untuk budidaya laut (12 hektar), 3,00\% untuk budidaya air payau (42 hektar) dan 4,72\% untuk budidaya air tawar $(2,356.7$ hektar) yang telah dimanfaatkan sebagai lahan perikanan budidaya; (3) Perikanan budidaya mempunyai kemampuan mengurangi tekanan terhadap lingkungan dari kegiatan pemanfaatan sumberdaya perikanan dari perairan umum melalui perekayasaan ekosistem perairan untuk mem-produksi ikan; (4) Pengelolaan pembudidayaan ikan menjadi tanggung jawab Pemerintah Daerah Kabupaten/Kota (UU Nomor 23 Tahun 2014).

Dinas Kelautan dan Perikanan Kabupaten Sukabumi telah memiliki Balai Benih Ikan Cimaja (BBI Cimaja) sebagai Unit Pelayanan Teknis Daerah (UPTD) untuk penyediaan benih bersertifikat Cara Pembenihan Ikan yang Baik (CPIB) dari induk-induk ikan bermutu. Balai Benih Ikan berfungsinya sebagai penghasil induk dan benih unggul untuk keperluan pembudidaya ikan di wilayah kabupaten, provinsi dan nasional.
UPTD BBI Cimaja juga bertugas untuk memberi kontribusi kepada Pendapatan Asli Daerah (PAD). Rincian produksi benih dan produksi ikan konsumsi Kabupaten Sukabumi serta PAD dari BBI Cimaja dapat dilihat pada Tabel 1.

Tabel 1. Produksi dan pendapatan BBI

\begin{tabular}{lccrr}
\hline No & Tahun & $\begin{array}{c}\text { Benih } \\
\text { Sukabumi } \\
(\times 1.000 \\
\text { ekor })\end{array}$ & $\begin{array}{c}\text { Benih } \\
\text { BBI } \\
(\times 1.000 \\
\text { ekor })\end{array}$ & \multicolumn{1}{c}{$\begin{array}{c}\text { PAD } \\
(\mathrm{Rp})\end{array}$} \\
\hline 1 & 2011 & 1.603 .144 & 0 & 0 \\
2 & 2012 & 1.989 .000 & 190 & 13.000 .000 \\
3 & 2013 & 2.579 .000 & 2.184 & 107.180 .000 \\
4 & 2014 & 3.353 .595 & 3.661 & 114.850 .000 \\
5 & 2015 & 3.700 .777 & 3.808 & 83.694 .300 \\
\hline
\end{tabular}

Sumber: Dislutkan, 2015 (diolah penulis)

BBI Cimaja berfungsi menyediakan induk dan benih siap sebar, maka keberadaan dan kinerja BBI Cimaja pada Dinas Perikanan dan Kelautan Kabupaten Sukabumi menjadi sangat penting terkait dengan peningkatan produksi ikan konsumsi air tawar.

Amstrong dan Baron (1998) mendefinisikan kinerja sebagai hasil pekerjaan yang mempunyai hubungan kuat dengan tujuan strategis organisasi, kepuasan konsumen dan memberikan kontribusi ekonomi. Wibowo (2007), kinerja mempunyai makna tidak hanya sebagai hasil kerja, tetapi juga bagaimana proses kerja berlangsung. Oleh karena itu, kinerja adalah tentang melakukan pekerjaan dan hasil yang dicapai dari pekerjaan tersebut atau tentang apa yang dikerjakan dan bagaimana cara mengerjakannya.

Norton dan Kaplan (1990) menyampaikan sebuah konsep pengukuran kinerja sebuah organisasi di masa depan. Konsep yang dikenal sebagai BSC menjabarkan peng-ukuran kinerja masa depan sebuah organisasi haruslah komprehensif, yang mencakup empat perspektif yaitu: keuangan, konsumen, proses bisnis internal dan pembelajaran-pertumbuhan. Dalam konsep ini, kinerja keuangan merupakan akibat atau hasil 
dari kinerja non keuangan (konsumen, proses bisnis, dan pembelajaran).

Ukuran-ukuran keuangan tidak memberikan gambaran yang riil mengenai keadaan perusahaan karena tidak memperhatikan hal-hal lain di luar sisi finansial, misalnya sisi pelanggan yang merupakan fokus penting bagi perusahaan dan karyawan, padahal dua hal tersebut merupakan roda penggerak bagi kegiatan perusahaan (Kaplan dan Norton, 1996).

Mulyadi dan Setyawan (1999), BSC tidak hanya sekedar alat pengukur kinerja perusahaan tetapi merupakan suatu bentuk transformasi strategik secara total kepada seluruh tingkatan dalam organisasi. Dengan pengukuran kinerja yang komprehensif tidak hanya merupakan ukuran-ukuran keuangan tetapi penggabungan ukuran-ukuran keuangan dan non keuangan maka perusahaan dapat menjalankan bisnisnya dengan lebih baik.

Gaspersz (2006), BSC merupakan sistem manajemen bagi perusahaan untuk berinvestasi dalam jangka panjang, untuk pelanggan (customer), pembelajaran dan pertumbuhan karyawan, termasuk manajemen (learning and growth), proses bisnis internal (sistem) demi memperoleh hasilhasil finansial yang memungkinkan perkembangan organisasi bisnis daripada sekedar mengelola bottom line untuk memacu hasil-hasil jangka pendek.

Marimin (2010), konsitensi yang sempurna dalam kehidupan nyata sulit diperoleh. Penilaian dengan konsistesi tinggi sangat diperlukan dalam pengambilan keputusan agar hasilnya akurat. AHP mengukur konsistensi menyeluruh dari berbagai pertimbangan melalui suatu rasio konsistensi. Nilai rasio konsistensi harus $10 \%$ atau kurang, jika lebih dari 10\% maka penilaian perlu diperbaiki. Terdapat tiga prinsip dalam memecahkan persoalan dengan analisis logis eksplisit: (1) Penyusunan Hierarki; (2) Penentuan Prioritas; (3) Konsistensi Logis.

Hasil evaluasi terhadap PT X disimpulkan pengukuran kinerja yang hanya berdasarkan pada aspek keuangan mulai dirasakan tidak memadai dalam menilai kinerja suatu perusahaan. Kinerja perusahaan meliputi aspek yang sangat luas. BSC menjawab tantangan itu. Dalam perspektif BSC, kinerja perusahaan paling tidak harus dilihat dalam empat aspek kinerja, yaitu aspek keuangan, pelanggan, pelanggan, proses bisnis internal, dan pembelajaran dan pertumbuhan. Dengan BSC, perusahaan mampu mengembangkan ukuranukuran kinerja yang bersumber dari visi dan misi perusahaan, sehingga mampu memberikan fokus pada strategi yang digunakan untuk mencapai visi dan misi tersebut (Suhendra, 2004).

Berdasarkas analisis terhadap PT Pindad sebelum menerapkan indikator efektivitas BSC dan sesudah menerapkan indikator efektivitas BSC disimpulkan bahwa efektivitas kinerja lebih tinggi setelah penerapan BSC dibanding sebelum penerapan BSC (Lestari, 2004 ).

Dalam penelitiannya terhadap 64 BUMD di Jawa Timur menemukan bahwa kinerja BUMD tergolong baik, terutama perspektif keuangan yang seluruh indikatornya (pertumbuhan pendapatan, efisiensi biaya, peningkatan laba dan pemanfaatan aktiva/strategi investasi). Namun ditemukan pula adanya beberapa perspektif yang perlu dibenahi, yaitu: perspektif pelanggan yakni pencapaian kuantitas produksi serta pangsa pasar yang dimiliki, perspektif proses bisnis internal yakni jaringan hubungan dengan pemasok dan pengendalian kualitas, serta perspektif pembelajaran dan pertumbuhan yakni peningkatan kinerja dan pemenuhan kebutuhan karyawan (Haris, 2004).

Hidayati (2010) kinerja Kebun Sidamanik Pematang Siantar PTP Nusantara IV (Persero) harus terus ditingkatkan baik dari sisi finansial maupun non finansial dengan tujuan untuk tetap menjaga nama baik perusahaan. Proses pengukuran kinerja yang selama ini digunakan adalah proses pembobotan yang mengabaikan saling keterkaitan antara strategi objektif. Metode yang selama ini digunakan didalam pembobotan adalah AHP.

Nugrahani dan Suliantoro (2015) PT Madubaru merupakan perusahaan yang produk utamanya adalah gula. Pengukuran kinerja rantai pasok menggunakan BSC yang mencakup 4 persepektif, yaitu finansial, pelanggan, proses internal serta pertumbuhan dan pembelajaran. Rating untuk menentukan Key Performance Indicator (KPI) PT Madubaru dari 1 sampai 5. Pembobotan dilakukan dengan AHP untuk menentukan prioritas perbaikan pada rantai pasok perusahaan.

Berdasarkan latar belakang tersebut, tujuan penelitian ini adalah: (1) Menghitung kinerja UPTD BBI Cimaja berdasarkan perspektif BSC; (2) Mengetahui faktor-faktor yang mempengaruhi kinerja UPTD BBI Cimaja berdasarkan perspektif BSC; dan (3) Menyusun strategi peningkatan kinerja UPTD BBI Cimaja berdasarkan perspektif BSC. 


\section{METODE PENELITIAN}

Penelitian dilakukan di UPTD BBI Cimaja Dinas Kelautan dan Perikanan Kabupaten Sukabumi berlamat di Jalan Raya Cisolok Km 11 Cimaja Palabuhanratu Kabupaten Sukabumi.
Diagram penentuan Strategi Peningkatan Kinerja BBI Cimaja tahap pertama ditunjukkan dalam Gambar 1. Penelitian terbagi dalam empat tahapan utama, metode dan keluaran yang dihasilkan pada setiap tahapan dapat dilihat pada Tabel 2.

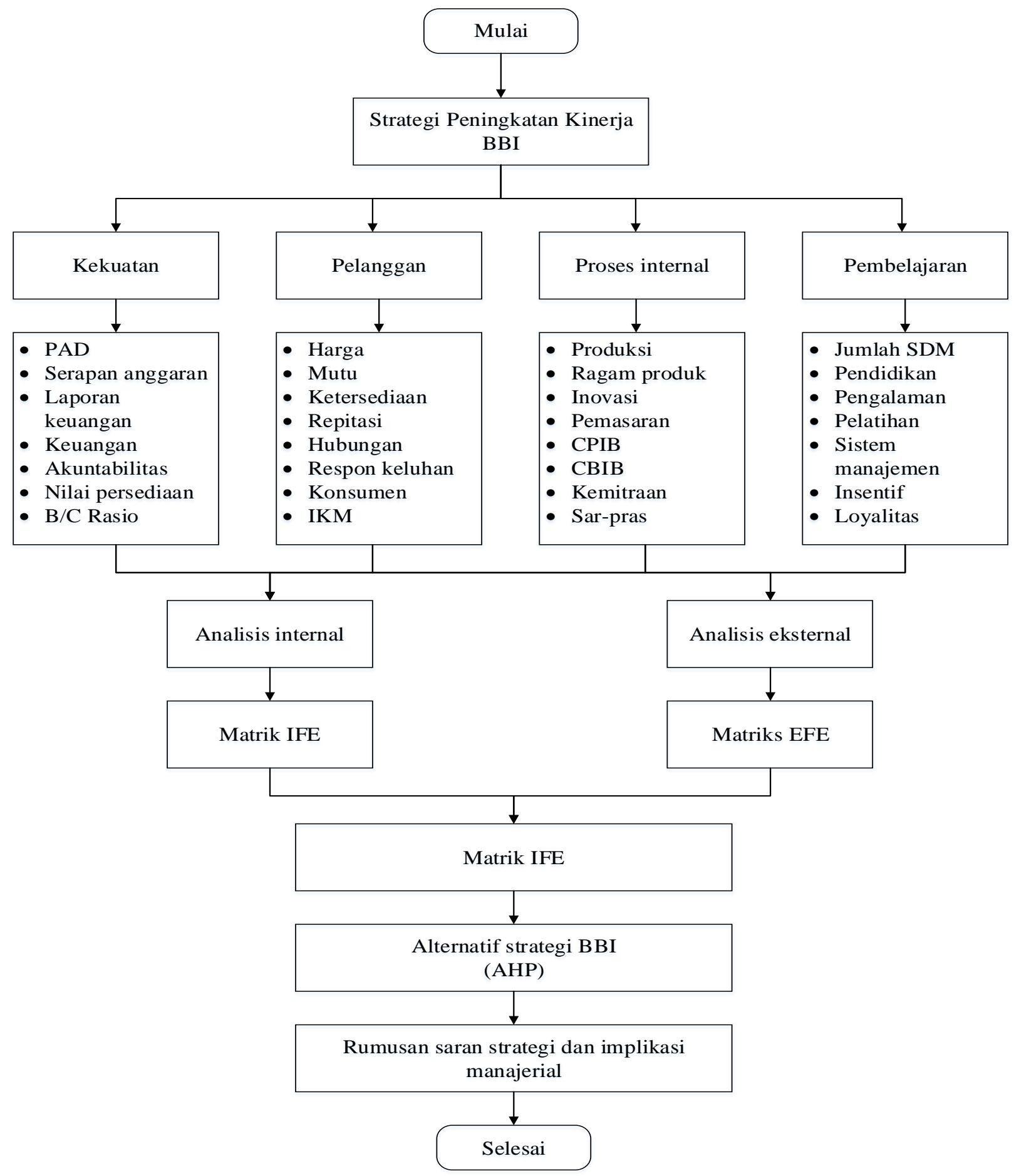

Gambar 1. Diagram alir penentuan strategi peningkatan kinerja 
Tabel 2. Tahapan penelitian, metode/tool dan keluaran

\begin{tabular}{|c|c|c|c|c|}
\hline No & Tahapan & Sub tahapan & Metode / tool & Keluaran \\
\hline 1 & $\begin{array}{l}\text { Analisis } \\
\text { Situasional }\end{array}$ & $\begin{array}{l}\text { Identifikasi Kondisi } \\
\text { Operasional BBI }\end{array}$ & $\begin{array}{l}\text { Wawancara, pengumpulan } \\
\text { data sekunder }\end{array}$ & Mengetahui kondisi terkini UPTD BBI \\
\hline 2 & Analisis BSC & Identifikasi Aspek BSC & Perbandingan Berpasangan & $\begin{array}{l}\text { Mengetahui Aspek kinerja prioritas } \\
\text { dan mengetahui kinerja BBI berdasar- } \\
\text { kan persepektif BSC }\end{array}$ \\
\hline 3 & $\begin{array}{l}\text { Analisis } \\
\text { SWOT }\end{array}$ & $\begin{array}{l}\text { Identifikasi Internal } \\
\text { dan Eksternal Faktor }\end{array}$ & $\begin{array}{l}\text { SWOT dan Perbandingan } \\
\text { Berpasangan }\end{array}$ & $\begin{array}{l}\text { Mengetahui posisi kekuatan, } \\
\text { kelemahan, peluang, ancaman BBI dan } \\
\text { alternatif strategi peningkatan kinerja }\end{array}$ \\
\hline 4 & $\begin{array}{l}\text { Penentuan } \\
\text { Strategi }\end{array}$ & $\begin{array}{l}\text { Mengolah alternatif } \\
\text { strategi, faktor dan } \\
\text { aktor peningkatan } \\
\text { kinerja BBI }\end{array}$ & $\mathrm{AHP} /$ Expert Choice 11 & $\begin{array}{l}\text { Penentuan strategi peningkatan } \\
\text { kinerja BBI }\end{array}$ \\
\hline
\end{tabular}

\section{Metode Pengumpulan dan Pengolahan Data}

Penelitian ini membutuhkan data primer dan data sekunder. Data primer dikumpulkan melalui wawancara mendalam kepada pakar berupa kuesioner meliputi: (1) Aspek BSC untuk mengetahui bobot faktor keuangan, pelanggan, proses bisnis internal, pembelajaran dan pertumbuhan di BBI Cimaja; (2) Analisis SWOT untuk mengetahui bobot dan rating faktor internal dan eksternal BBI Cimaja; (3) Penentuan strategi peningkatan kinerja BBI Cimaja. Data sekunder mengenai kinerja BBI Cimaja diperoleh dari studi kepustakaan, UPTD BBI Dinas kelautan dan Perikanan Kabupaten Sukabumi dan lembaga penelitian maupun pemerintah lainnya.

\section{Analisis Situasional}

Analisis situasional diperoleh dari laporan BBI Cimaja dan wawancara dengan personil BBI Cimaja untuk mengetahui kondisi terkini UPTD BBI. Analisis BSC diperoleh dari narasumber pakar untuk mengetahui aspek kinerja prioritas dan mengetahui kinerja BBI berdasarkan perspektif BSC. Analisis SWOT diperoleh dengan mengidentifikasi faktor internal dan eksternal BBI Cimaja untuk mengetahui posisi kekuatan, kelemahan, peluang, ancaman BBI dan alternatif strategi peningkatan kinerja. Penentuan strategi peningkatan kinerja dalam rangka memenuhi tugas pokok dan fungsi BBI dicapai dengan mengolah alternatif strategi, faktor dan aktor peningkatan kinerja BBI.

\section{Analisis Balanced Scorecard}

Untuk mengetahui kinerja BBI maka dilakukan serangkaian analisis dari data yang diperoleh berdasarkan perspektif BSC. Alat bantu untuk menghitung bobot tujuan kinerja adalah dengan expert choice 11. Pembobotan tujuan dimulai dengan mengisi matrik perbandingan berpasangan: (1) Keuangan; (2) Pelanggan; (3) Proses bisnis internal; (4) Pembelajaran pertumbuhan.

Matriks perbandingan berpasangan perspektif BSC menghasilkan bobot dan dinilai rating 1 sampai 5 (Suliantoro, 2015) Pengukuran kinerja ditunjukan dalam Tabel 3.

Tabel 3. Skala rating pengukuran kinerja

\begin{tabular}{ccc}
\hline Rating & Capaian $(\%)$ & Nilai \\
\hline 1 & $<40$ & Sangat Tidak Baik \\
2 & $40-59$ & Tidak Baik \\
3 & $60-79$ & Cukup Baik \\
4 & $80-99$ & Baik \\
5 & 100 & Sangat Baik \\
\hline
\end{tabular}

\section{Analisis SWOT BBI}

Berdasarkan analisis internal maupun eksternal, diperoleh butir-butir Kekuatan, Kelemahan, Peluang, Ancaman Organisasi, maka dapat ditentukan pembobotan dari masingmasing butir tersebut. Bobot dari setiap faktor dari Strength, Weakness, Opportunity, Threaths diberi nilai $=1,00$. (Muspitawati, 2002 dalam Marimin, 2010). Pembobotan menggunakan perbandingan berpasangan melalui kuesioner pakar, sedangkan untuk masing-masing rating faktor melalui kuesioner seluruh karyawan BBI. Rating faktor kekuatan diberi kriteria; Rating 1 (Sedikit Kuat), Rating 2 (Agak Kuat), Rating 3 (Kuat), Rating 4 (Sangat Kuat). Rating faktor Kelemahan diberi kriteria; Rating 1 (Sedikit Lemah), Rating 2 (Agak Lemah), Rating 3 (Lemah), Rating 4 (Sangat Lemah). Untuk Rating faktor Peluang diberi kriteria; Rating 1 (Sedikit Peluang), Rating 2 (Agak Peluang), Rating 3 (Peluang), 
Rating 4 (Sangat Peluang). Rating faktor Ancama diberi kriteria; Rating 1 (Sedikit Mengancam), Rating 2 (Agak Mengancam), Rating 3 (Mengancam), Rating 4 (Sangat Mengancam). Faktor internal dan eksternal yang telah ditentukan selanjutnya diolah untuk mengetahui posisi BBI. Pembobotan dilakukan dengan responden pakar dengan rataan geometrik diolah dengan expert choice 11.

\section{Penentuan Strategi}

Proses penentuan strategi menggabungkan kerangka BSC dengan formulasi strategi dalam analisis SWOT, yaitu berdasarkan analisis internal dan eksternal yang disesuaikan dengan visi, misi dan tujuan organisasi kemudian dianalisis dengan AHP dan alat bantu expert choice 11, selanjutnya seluruh kekuatan dan kelemahan serta peluang dan ancaman dimasukkan ke dalam matriks SWOT yang menunjukkan kondisi kinerja BBI saat ini dalam posisi di antara empat kuadran, yang merupakan petunjuk penyusunan strategi peningkatan kinerja BBI. Adapun setiap kuadran memiliki arti:

- Kuadran I: Situasi yang sangat menguntungkan BBI memiliki peluang dan kekuatan sehingga dapat memanfaatkan peluang yang ada. Strategi yang harus diterapkan dalam kondisi ini adalah mendukung kebijakan pertumbuhan yang agresif (Strategi SO).

- Kuadran II: Meskipun menghadapi berbagai ancaman, BBI masih memiliki kekuatan dari segi internal. Strategi yang harus diterapkan adalah menggunakan kekuatan untuk memanfaatkan peluang jangka panjang dengan strategi diversifikasi (Strategi ST).

- Kuadran III: BBI menghadapi peluang pasar yang sangat besar, tetapi di lain pihak menghadapi beberapa kendala/kelemahan internal. Fokus strategi BBI adalah meminimalkan masalah-masalah internal sehingga dapat merebut peluang pasar yang lebih baik (Strategi WO).

- Kuadran IV: BBI menghadapi berbagai ancaman dan kelemahan internal.

\section{Tahapan Kerja Pembobotan Strategi AHP}

1. Penyusunan Hierarki. Strategi yang akan dipilih diuraikan unsur unsurnya, yaitu: (1) Tujuan; (2) Aktor pelaksanaan strategi; (3) Faktor yang memengaruhi pelaksanaan strategi; (4) Alternatif Strategi pilihan berdasarkan analisis SWOT. Tujuan untuk menentukan pilihan strategi kinerja berdasarkan perspektif BSC adalah: (1) Keuangan; (2) Pelanggan; (3) Proses bisnis internal; (4) Pembelajaran pertumbuhan. Aktor pelaksanaan strategi adalah: (1) Bappeda; (2) Bagian program dan keuangan; (3) UPTD BBI; (Unit Pembenihan Rakyat atau UPR Mitra). Faktor yang mempengaruhi pelaksanaan strategi: (1) Anggaran; (2) SDM BBI; (3) Sarana dan prasarana BBI; (4) Standar Operasional Prosedur BBI; (5) Indeks Kepuasan Masyarakat. Alternatif strategi diperoleh dari masukan pakar berdasarkan analisis faktor internal dan eksternal, lima alternatif yang akan menjadi pilihan.

2. Penilaian Tujuan, Aktor, Faktor dan Alternatif, melalui perbandingan berpasangan skala 1 sampai 9.

3. Penentuan Prioritas Nilai, nilai perbandingan berpasangan dari tujuan, aktor, faktor dan alternatif diolah untuk menentukan peringkat relatif dari seluruh alternatif.

4. Konsistensi Logis. Data primer yang diperoleh dari responden pakar yang dipakai adalah data yang memiliki Consistency Ratio yaitu dibawah $10 \%$

\section{HASIL DAN PEMBAHASAN}

\section{Analisis Situasional}

UPTD BBI Cimaja dibentuk sejak tahun 2011, dan dikelola oleh sebuah manajemen yang dipimpin oleh kepala dan kepala subbagian tata usaha yang merangkap sebagai manajer pengendali mutu terhadap enam divisi (Produksi, Pelayanan, Pemasaran, Tata Kelola Air, Kesehatan Lingkungan dan Data, dan Informasi) dengan total pekerja sebanyak 12 orang. Anggaran atau pembiayaan bersumber dari APBD yang bersumber dari usulan pemerintah daerah (c.q. Dinas Kelautan dan Perikanan serta Badan Perencana Pembangunan Daerah) yang disetujui oleh Dewan Perwakilan Rakyat Daerah Kabupaten Sukabumi. Secara teknis, Kepala UPTD BBI Cimaja bertanggung jawab langsung kepada Bupati Sukabumi melalui Kepala Dinas Kelautan dan Perikanan. Luas lahan keseluruhan $12.075 \mathrm{~m}^{2}$, sedangkan luas lahan produktif $10.500 \mathrm{~m}^{2}$. Sumber air yang digunakan berasal dari sungai Cimaja melalui saluran irigasi dan pipanisasi. Jenis komoditas produksi benih sebar pada UPTD Balai Benih Ikan adalah benih ikan patin, lele, nila, mas, bawal dan ikan hias jenis Koi. 


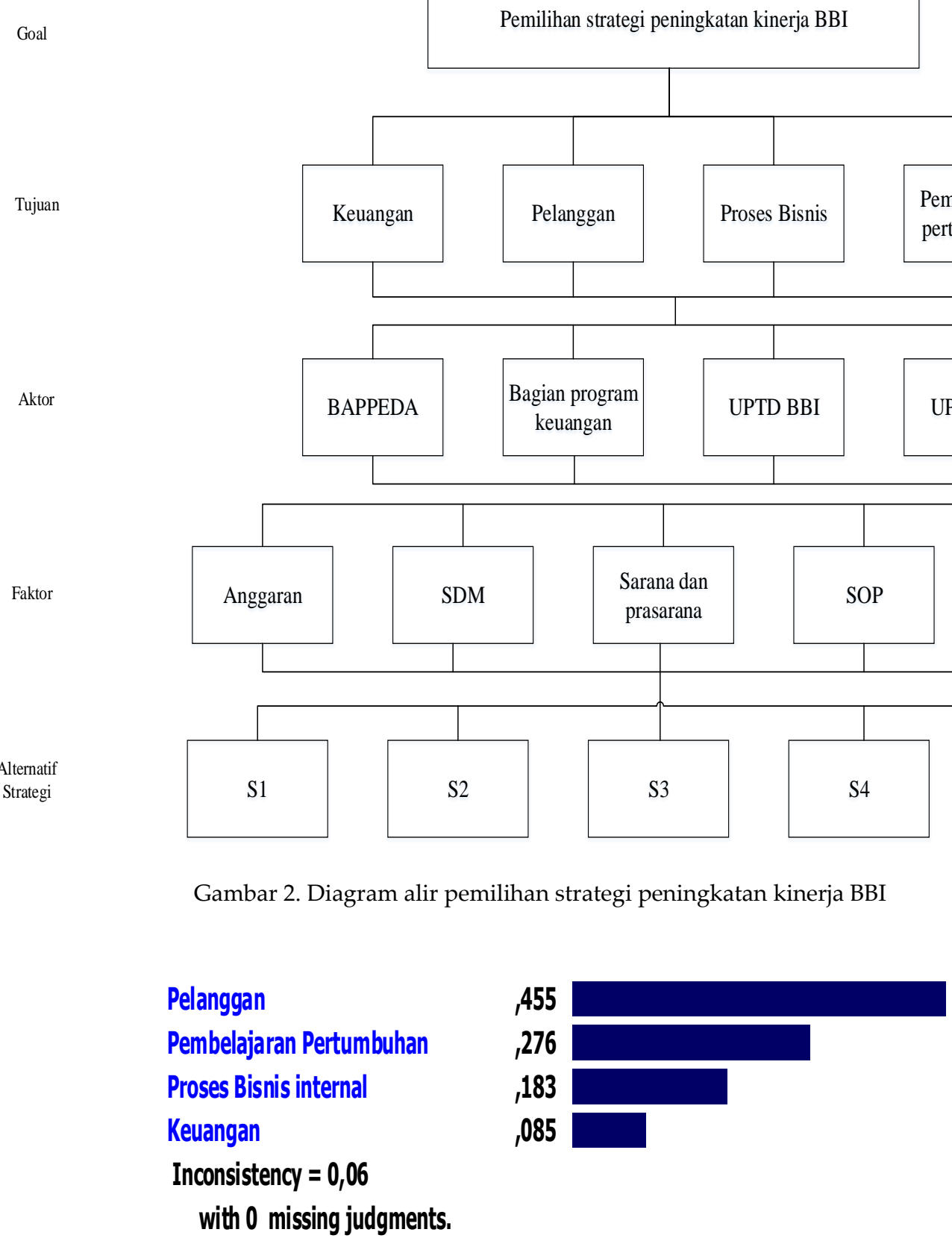

Gambar 3. Diagram batang prioritas strategi peningkatan kinerja UPTD BBI Cimaja berdasarkan perspektif BSC

Alokasi anggaran rata rata tiga tahun terakhir untuk mendukung operasional BBI Cimaja adalah Rp276.034.436 dan rata rata penyerapan anggaranya adalah Rp273.359.167 atau 99,03\%.

Rataan PAD yang bersumber dari penjualan benih sebar BBI adalah 98,62\%, pada tahun 2015 PAD hanya mencapai $76,09 \%$. Target produksi benih sebar pada BBI Cimaja dari tahun 2013 sampai tahun 2015 belum pernah tercapai, rata-rata capaian produksi adalah $40,73 \%$, hal ini berbanding terbalik dengan capaian realisasi anggaran yang terealisasi rata-rata $99,03 \%$.

\section{Analisis BSC}

Pengolahan data dari responden 11 pakar, 5 pakar yang konsisten dikombinasikan diperoleh prioritas utama kinerja BBI adalah: (1) Pelanggan dengan bobot 0,455 ; (2) Pembelajaran pertumbuhan dengan bobot 0,276; (3) Proses bisnis internal dengan bobot 0,183 ; (4) Keuangan dengan bobot 0,085. Hasil perhitungan elemen BSC dengan expert choice 11 ditunjukkan Gambar 3. 
Berdasarkan Tabel 4, 5, 6, 7 maka kinerja BBI Cimaja Dinas Kelautan dan Perikanan Kabupaten Sukabumi tahun 2015 untuk perspektif pelanggan bernilai cukup baik, pembelajaran dan pertumbuhan bernilai tidak baik, perspektif proses bisnis internal bernilai sangat tidak baik, keuangan cukup baik.

Tabel 4. Kinerja BBI Tahun 2015 berdasarkan perspektif pelanggan

\begin{tabular}{clcccc}
\hline No & Pelanggan & Realisasi & Rating & Bobot & Nilai \\
\hline 1 & Harga & Sangat Baik & 5 & 0,026 & 0,13 \\
2 & Mutu & Baik & 4 & 0,161 & 0,644 \\
3 & Ketersediaan & $47,55 \%$ & 2 & 0,197 & 0,394 \\
4 & Reputasi & Baik & 4 & 0,075 & 0,3 \\
5 & Hubungan & Baik & 4 & 0,096 & 0,384 \\
6 & Respon & Baik & 4 & 0,133 & 0,532 \\
& Keluhan & & 2 & 0,158 & 0,316 \\
7 & Konsumen & 230 & 2 & 0,154 & 0,616 \\
8 & IKM & 80,83 & 4 & & 3,316 \\
\hline & \multicolumn{5}{c}{ Nilai Akhir } \\
\hline
\end{tabular}

Tabel 5. Kinerja BBI Tahun 2015 berdasarkan perspektif pembelajaran dan pertumbuhan

\begin{tabular}{clccrc}
\hline No & Pembelajaran & Realisasi & Rating & Bobot & Nilai \\
\hline 1 & Jumlah SDM & 12 & 5 & 0,078 & 0,390 \\
2 & Pendidikan & SMA & 3 & 0,103 & 0,309 \\
3 & Pengalaman & 5 Tahun & 3 & 0,175 & 0,525 \\
4 & Pelatihan & $1 \times$ & 1 & 0,119 & 0,119 \\
& Sistem & & & & \\
5 & Manajemen & Terbuka & 4 & 0,208 & 0,416 \\
6 & Insentif & Tdk & 1 & 0,140 & 0,140 \\
& Ada & & & \\
7 & Kepuasan & Baik & 4 & 0,176 & 0,704 \\
& Karyawan & Nilai Akhir & & & \\
\hline \multicolumn{7}{c}{} \\
\hline
\end{tabular}

Tabel 6. Kinerja BBI Tahun 2015 berdasarkan perspektif proses bisnis internal

\begin{tabular}{clcccc}
\hline No & Proses Internal & Realisasi & Rating & Bobot & Nilai \\
\hline 1 & Produksi & $48 \%$ & 2 & 0,083 & 0,166 \\
2 & Ragam Produk & 6 & 4 & 0,081 & 0,324 \\
& Inovasi & & & & \\
3 & Pemasaran & 2 & 2 & 0,055 & 0,110 \\
& Optimalisasi & & & & \\
4 & Proses & 1 & 1 & 0,168 & 0,168 \\
5 & Sertifikasi CPIB & 3 & 2 & 0,229 & 0,458 \\
6 & Sertifikasi CBIB & 2 & 2 & 0,183 & 0,366 \\
7 & Kemitraan & $50 \%$ & 2 & 0,085 & 0,170 \\
& Peningkatan & & & & \\
8 & Sarpras & $40 \%$ & 2 & 0,117 & 1,596 \\
\hline & & & Jumlah & 1,596 \\
\hline
\end{tabular}

Tabel 7. Kinerja BBI Tahun 2015 berdasarkan perspektif keuangan

\begin{tabular}{cccccc}
\hline No & \multicolumn{1}{c}{ Keuangan } & Realisasi & Rating & Bobot & Nilai \\
\hline 1 & PAD & 83.694 .300 & 3 & 0,105 & 0,315 \\
2 & $\begin{array}{l}\text { Serapan } \\
\text { Anggaran }\end{array}$ & 294.761 .000 & 5 & 0,104 & 0,520 \\
3 & $\begin{array}{l}\text { Laporan } \\
\text { Keuangan }\end{array}$ & 5 & 5 & 0,178 & 0,890 \\
4 & $\begin{array}{l}\text { Penyimpangan } \\
\text { Keuangan }\end{array}$ & 5 & 5 & 0,321 & 1,605 \\
6 & $\begin{array}{l}\text { Nilai Persediaan } \\
6\end{array}$ & 93.855 .000 & 1 & 0,172 & 0,172 \\
\hline & $-0,88$ & 1 & 0,121 & 0,12 \\
\hline
\end{tabular}

\section{Analisis SWOT}

Data pada Tabel 8 menunjukkan faktorfaktor yang memengaruhi kinerja balai benih ikan berdasarkan perspektif BSC. Faktor yang berpengaruh terhadap kinerja BBI selanjutnya diperjelas dalam Tabel 9 dan 10.

Tabel 8. Faktor yang memengaruhi kinerja UPTD BBI Cimaja berdasarkan prespektif BSC

\begin{tabular}{|c|c|c|}
\hline No. & $\begin{array}{c}\text { Aspek/Perspektif } \\
B S C \\
\end{array}$ & $\begin{array}{c}\text { Faktor-faktor } \\
\text { yang Memengaruhi Kinerja }\end{array}$ \\
\hline$(1)$ & $(2)$ & $(3)$ \\
\hline 1. & Keuangan & $\begin{array}{l}\text { 1. Peningkatan pendapatan } \\
\text { 2. Dukungan APBD }\end{array}$ \\
\hline & Pelanggan & $\begin{array}{l}\text { 1. Harga benih } \\
\text { 2. Mutu benih } \\
\text { 3. Ketersediaan benih } \\
\text { 4. Peningkatan konsumen } \\
\text { 5. Loyalitas konsumen (adanya } \\
\text { kompetisi unit pembenihan ) } \\
\text { 6. Peningkatan konsumsi ikan } \\
\text { 7. Reputasi BBI } \\
\text { 8. Peningkatan Indeks } \\
\text { Kepuasan Masyarakat } \\
\text { 9. Kemitraan UPR } \\
\text { 10. Respon keluhan pelanggan }\end{array}$ \\
\hline & Proses Internal & $\begin{array}{l}\text { 1. Keragaman benih } \\
\text { 2. Kecukupan kolam } \\
\text { pendederan } \\
\text { 3. Optimalisasi proses produksi } \\
\text { 4. Sertifikasi benih } \\
\text { 5. Debit sumber air } \\
\text { 6. Pencemaran sumber air }\end{array}$ \\
\hline & $\begin{array}{l}\text { Pembelajaran dan } \\
\text { Pertumbuhan }\end{array}$ & $\begin{array}{l}\text { 1. Pendidikan SDM } \\
\text { 2. Pengalaman SDM } \\
\text { 3. Keterbukaan manajemen } \\
\text { 4. Insentif/disinsentif } \\
\text { 5. Loyalitas SDM }\end{array}$ \\
\hline
\end{tabular}

Data pada Tabel 9 menunjukkan matriks IFE usaha UPTD BBI Cimaja. Mutu benih yang dihasilkan merupakan kekuatan utama UPTD BBI 
Cimaja (nilai skor 0,872). Keterbatasan kolam pendederan (nilai skor 1,216) menjadi kelemahan utama pengembangan usaha UPTD BBI Cimaja. Skor kekuatan lebih tinggi dibandingkan kelemahan (nilai skor 0,853) bahwa dengan memanfaatkan kekuatan yang dimiliki, manajemen UPTD BBI Cimaja seharusnya dapat mengurangi bahkan menutupi kelemahan yang dimiliki.

Tabel 9. Faktor strategik internal (Matriks IFE) UPTD BBI Cimaja

\begin{tabular}{|c|c|c|c|c|}
\hline \multirow{2}{*}{ No } & \multirow{2}{*}{ Faktor Internal } & Bobot & Rating & Skor \\
\hline & & (a) & (b) & (a) $x(b)$ \\
\hline \multicolumn{5}{|c|}{ Kekuatan } \\
\hline 1 & Mutu benih & 0,218 & 4 & 0,872 \\
\hline 2 & Harga benih & 0,107 & 4 & 0,428 \\
\hline 3 & Benih bersertifikat & 0,159 & 3 & 0,477 \\
\hline 4 & Respon keluhan pelanggan & 0,158 & 4 & 0,632 \\
\hline 5 & Keterbukaan manajemen & 0,075 & 4 & 0,300 \\
\hline 6 & Dukungan APBD & 0,136 & 4 & 0,544 \\
\hline \multirow[t]{2}{*}{7} & Pengalaman SDM & 0,148 & 4 & 0,592 \\
\hline & Jumlah & 1,000 & & 3,845 \\
\hline \multicolumn{5}{|c|}{ Kelemahan } \\
\hline 1. & Ketersediaan benih terbatas & 0,083 & 3 & 0,249 \\
\hline 2. & Kolam pendederan terbatas & 0,304 & 4 & 1,216 \\
\hline 3. & Proses produksi tidak optimal & 0,199 & 3 & 0,597 \\
\hline 4. & Tidak ada insentif & 0,155 & 2 & 0,310 \\
\hline 5. & Loyalitas SDM rendah & 0,157 & 2 & 0,314 \\
\hline \multirow[t]{3}{*}{6.} & Pendidikan SDM rendah & 0,102 & 3 & 0,306 \\
\hline & Jumlah & 1,000 & & 2,992 \\
\hline & \multicolumn{3}{|c|}{ Jumlah Skor Kekuatan-Kelemahan } & 0,853 \\
\hline
\end{tabular}

Data pada Tabel 10 menunjukkan matriks EFE usaha UPTD BBI Cimaja. Nampak reputasi UPTD BBI Cimaja di kalangan pembudidaya ikan (nilai skor 1,340) sebagai penghasil benih dengan mutu yang baik menjadi faktor utama peluang pengembangan UPTD BBI Cimaja itu sendiri. Reputasi ini ditunjang oleh mandat dari pemerintah kepada UPTD BBI Cimaja sebagai salah satu anggota pusat indukan nasional (Broodstock center). Sebaliknya, penurunan debit sumber air (nilai skor 1,372) menjadi ancaman utama bagi keberlanjutan usaha UPTD BBI Cimaja. Perlu diperhatikan adalah nilai skor total ancaman lebih tinggi dibandingkan dengan nilai skor total peluang sebagaimana ditunjukkan oleh nilai skor total Peluang-Ancaman sebesar -0,653. Dalam jangka panjang, kondisi ini akan sangat memengaruhi kinerja bahkan keberlanjutan usaha UPTD BBI Cimaja.

\section{Penentuan Strategi}

Hasil AHP terhadap prioritas peningkatan kinerja UPTD berdasarkan perspektif BSC yang ditampilkan pada Gambar 3 menunjukkan bahwa perspektif pelanggan menjadi prioritas utama.
Alternatif strategi yang diperoleh dari penggabungan kerangka BSC dan analisis SWOT adalah (S1) BBI mengoptimalisasi APBD untuk memproduksi benih bermutu dan bersertifikat dengan harga yang bersaing dengan unit pembenihan sejenis untuk dapat bersaing sehat dengan unit pembenihan sejenis $\left(\mathrm{S}_{1,2,3,4,5,6,7} \& \mathrm{~T}_{3}\right) ;(\mathrm{S} 2)$ Pembangunan kolam pembenihan baru melalui dukungan APBD agar bisa meningkatkan produksi dan ragam benih untuk meningkatkan jumlah

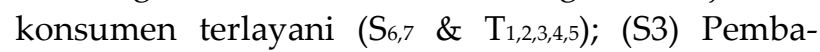
ngunan bak penampungan dan penyaringan untuk mengatasi pencemaran sumber air sehingga mutu benih terjaga $\left(S_{1,6,7} \& T_{5}\right)$; (S4) Merespon setiap keluhan pelanggan untuk meningkatkan Indeks Kepuasan Masyarakat dan Reputasi BBI terjaga $\left(\mathrm{S}_{4,5,7} \& \mathrm{O}_{3,4}\right)$; (S5) Mengoptimalkan peran kemitraan untuk mengatasi kolam pendederan yang terbatas dan meningkatkan produksi ( $\left.\mathrm{W}_{1,2} \& \mathrm{O}_{5}\right)$.

Tabel 10. Faktor strategik eksternal (matriks EFE) UPTD BBI Cimaja

\begin{tabular}{|c|c|c|c|c|}
\hline \multirow{2}{*}{ No } & \multirow{2}{*}{ Faktor Internal } & Bobot & Rating & Skor \\
\hline & & (a) & (b) & (a)x(b) \\
\hline \multicolumn{5}{|c|}{ Peluang } \\
\hline 1 & Peningkatan konsumsi ikan & 0,085 & 1 & 0,085 \\
\hline 2 & Peningkatan konsumen & 0,194 & 3 & 0,582 \\
\hline 3 & Peningkatan IKM & 0,236 & 2 & 0,472 \\
\hline 4 & Reputasi BBI & 0,335 & 4 & 1,340 \\
\hline \multirow[t]{2}{*}{5} & Kemitraan UPR & 0,151 & 2 & 0,302 \\
\hline & Jumlah & 1,000 & & 2,781 \\
\hline \multicolumn{5}{|c|}{ Ancaman } \\
\hline 1. & $\begin{array}{l}\text { Konsumen terlayani } \\
\text { berkurang }\end{array}$ & 0,180 & 4 & 0,720 \\
\hline 2. & Debit air menurun & 0,343 & 4 & 1,372 \\
\hline 3. & Unit pembenihan lain & 0,087 & 2 & 0,174 \\
\hline 4. & Keragaman benih & 0,132 & 1 & 0,132 \\
\hline \multirow[t]{4}{*}{5.} & Pencemaran sumber air & 0,259 & 4 & 1,036 \\
\hline & Jumlah & 1,000 & & 3,434 \\
\hline & \multicolumn{2}{|c|}{ Jumlah Skor Peluang-Ancaman } & & -0.653 \\
\hline & \multicolumn{3}{|c|}{ Gabungan Skor Peluang+Ancaman } & 3,108 \\
\hline
\end{tabular}

Penentuan strategi berdasarkan faktor yang paling berpengaruh, yaitu (1) Ketersediaan; (2) Mutu; (3) Konsumen terlayani; (4) Indeks kepuasan Masyarakat; dan (5) Respon Keluhan. Strategi terpilih dari hasil perhitungan AHP meliputi unsur unsur Tujuan, aktor pelaksanaan strategi dan faktor yang memengaruhi pelaksanaan strategi adalah Pembangunan kolam pembenihan baru melalui dukungan APBD agar bisa meningkatkan produksi dan ragam benih untuk meningkatkan jumlah konsumen terlayani, ditunjukkan dalam Gambar 4 dan 5 . 
KKP instance -- Synthesis with respect to:

Goal:Pemilihan Altarnatif Strategi Peningkatan Kinerja BB

Overall Inconsistency $=, 08$

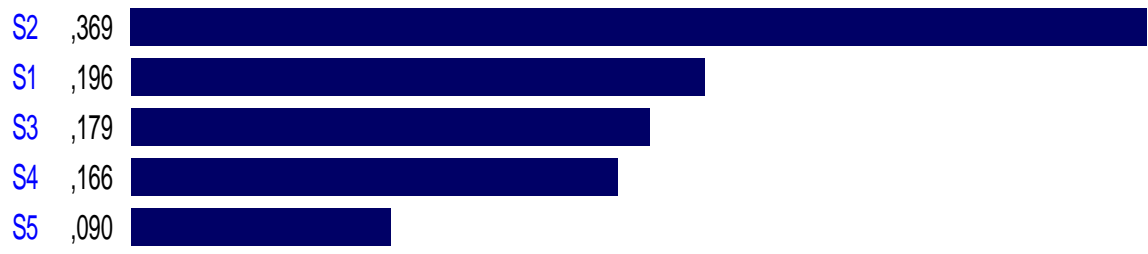

Gambar 4. Prioritas strategi peningkatan kinerja BBI

Priorities with respect to:

Combined

Strategi Peningkatan Kinerja BBI

$>$ Pelanggan

Ketersediaan
Mutu
Konsumen Terlayani
Indeks Kepuasan Masyarakat
Respon Keluhan
Hubungan
Reputasi
Harga
Inconsistency = 0,03
$\quad$ with 0 missing judgments.

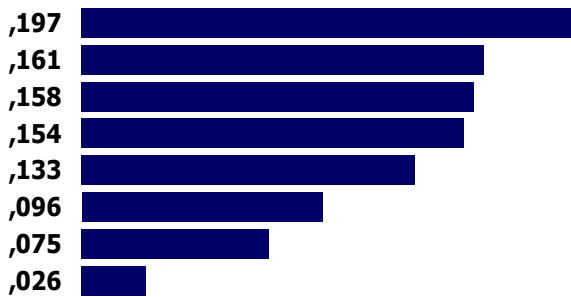

Gambar 5. Faktor kinerja pelanggan

\section{Implikasi Manajerial}

Hasil AHP terhadap prioritas peningkatan kinerja UPTD berdasarkan perspektif BSC yang ditampilkan pada Gambar 3 menunjukkan bahwa perspektif pelanggan menjadi prioritas utama. Pemilihan strategi pembangunan kolam pembenihan baru menempatkan manajemen BBI adalah aktor yang paling berperan dalam pelaksanaan strategi yang dipilih, faktor yang paling menentukan terlaksananya strategi adalah anggaran. Manajemen BBI, bagian program dan keuangan Dinas Kelautan dan Perikanan, Bappeda Kabupaten Sukabumi bersama sama menyusun studi kelayakan untuk bisa melaksanakan strategi terpilih.

\section{KESIMPULAN}

Pelanggan menjadi prioritas utama kinerja BBI Cimaja, Tahun 2015 kinerja aspek pelanggan cukup baik. Kinerja aspek pelanggan meskipun cukup baik akan cenderung menurun karena harapan pelanggan adalah ketersediaan benih ketika dibutuhkan, sementara terbatasnya lahan
BBI dan debit air yang terus menurun menyebabkan target produksi benih tidak tercapai. Keterbatasan lahan menjadi penyebab terbatasnya sarana produksi yang sangat dibutuhkan untuk meningkatkan produksi, konsumen teryanai dan menjaga kualitas benih.

\section{DAFTAR PUSTAKA}

Fattah, N. 1999. Landasan Manajemen. Bandung: Rosda Karya.

Gaspersz, V. 2006. Balance Scorecrad dengan Six Sigma untuk Organisasi Bisnis dan Pemerintah. Jakarta: PT Gramedia Pustaka Utama.

Gomes, FC. 2003. Manajemen Sumber Daya Manusia. Yogyakarta: Andi Offset.

Griffin, RW. 1987. Management, Second Edition, Boston: Houhton Mifflin Press.

Haris, R. Abdul, 2004, Pengaruh Manajemen Sumber Daya Manusia Strategik Terhadap Kinerja BUMD Serta Implikasinya dalam PAD Kota/Kabupaten di Jawa Timur, 
Disertasi Program Pasca Sarjana Merdeka Malang.

Kaplan, RS., DP. Norton. 2000. Balanced Scorecard: Menerapkan Strategi Aksi. Jakarta: PT Erlangga.

Keban, YT. 2004. Enam Dimensi Strategis Administrasi Publik: Konsep, Teori, dan Isu. Yogyakarta. Gava Media.

Lestari, DI. 2004. Analisis Efektovitas Kinerja Sebelum dan sesudah Penerapan Balanced Scorecard Pada PT. PINDAD, Sripsi Fakultas Ekonomi Universitas widyatama Bandung.

Mahsun, M. 2009. Pengukuran Kinerja Sektor Publik. Yogyakarta: BPFE.

Marimin, 2010. Aplikasi Teknik Pengambilan Keputusan dalam Manajemen Rantai Pasok, IPB Press.

Mulyadi. 2001. Balanced Scorecard: Alat Manajemen Kontemporer untuk Pelipatgandaan Kinerja Keuangan Perusahaan. Jakarta: Salemba Empat.

Mulyadi, J. Setiawan. 1999. Sistem Perencanaan dan Pengendalian Manajemen: Sistem Pelipatgandaan Kinerja Perusahaan. Edisi 1. Yogyakarta: Aditya Media.

Nugrahani, D., H. Suliantoro. 2015. Pengukuran dan Evaluasi Kinerja Supply Chain Dengan Menggunakan Pendekatan Balanced Scorecard-Analytical Network Proces (BSC-ANP) di PT. Madubaru Yogyakarta, Prosiding SNST, ke-6 Tahun 2015.
Putra, B.I. 2014. Jurnal Teknik Industri Universitas Muhamadiyah Sidoarjo.

Rangkuti, F. 2014. SWOT Balanced Scorecard: Teknik Menyusun Strategi Korporat yang Efektif plus Cara Mengelola Kinerja dan Resiko. Jakarta: PT Gramedia Pustaka Utama.

Rivai, V. 2005. Performance Appraisal. Jakarta: PT Raja Grafindo Persada.

Samsudin, S. 2005. Manajemen Sumber Daya Manusia. Bandung: Pustaka Setia.

Sedarmayanti. 2001. Sumberdaya Manusia dan Produktivitas Kerja. Bandung: Mandar Maju.

Simamora, H. 2004. Manajemen Sumberdaya Manusia. Yogyakarta: YKPN.

Simon, R. 2000. Perfomance Measurement \& Control System for Implementing Strategy. New Jersey: Prentice hall. Inc.

Suhendra, M. 2004. Jurnal Kajian Ekonomi dan Keuangan Volume 8 Nomor 2 tahun 2004

Suliantoro, H., D. Nugrahani. 2015 Pengukuran dan Evaluasi Kinerja Suply Chain dengan Menggunakan Pendekatan Balanced Scorecard. Jurnal Fakultas Tekhnik Universitas Wahid Hasyim Semarang.

Tangkilisan, HNS. 2005. Manajemen Publik. Jakarta: PT Grasindo.

Wibowo. 2007. Manajemen Kinerja. Jakarta: PT Rajagrafindo Persada.

Yuwono, S., S. Edy, I. Muhammad. 2007. Petunjuk Praktis Penyusunan Balanced Scorecard Menuju Organisasi yang Berfokus pada Strategi. Edisi 4. Jakarta: PT Gramedia Pustaka Utama. 